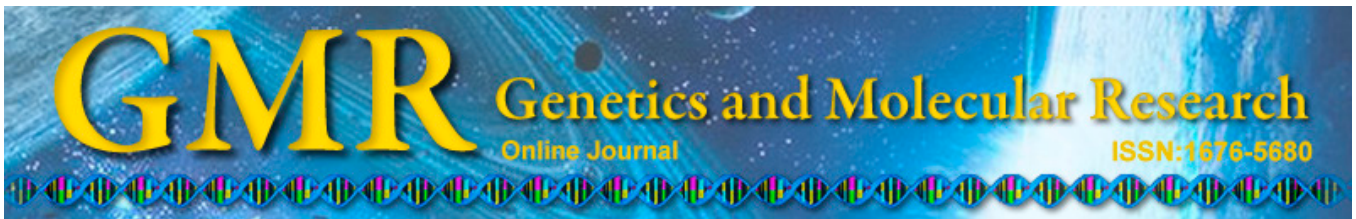

\title{
Distribution of constitutive heterochromatin in Triatoma melanocephala (Hemiptera, Triatominae)
}

\author{
K.C.C. Alevi ${ }^{1}$, J.A. Rosa ${ }^{2}$ and M.T.V. Azeredo-Oliveira ${ }^{1}$ \\ ${ }^{1}$ Laboratório de Biologia Celular, Departamento de Biologia, \\ Instituto de Biociências, Letras e Ciências Exatas, \\ Universidade Estadual Paulista "Júlio de Mesquita Filho", \\ São José do Rio Preto, SP, Brasil \\ ${ }^{2}$ Laboratório de Parasitologia, Departamento de Ciências Biológicas, \\ Faculdade de Ciências Farmacêuticas, \\ Universidade Estadual Paulista "Júlio de Mesquita Filho", \\ Araraquara, SP, Brasil \\ Corresponding author: K.C.C. Alevi \\ E-mail: kaiochaboli@hotmail.com
}

Genet. Mol. Res. 13 (3): 7899-7903 (2014)

Received January 29, 2014

Accepted August 14, 2014

Published September 29, 2014

DOI http://dx.doi.org/10.4238/2014.September.29.2

\begin{abstract}
In principle, Triatoma melanocephala was included in the Brasiliensis subcomplex on the basis of morphological parameters and geographical layout, since there were no other relevant data available in the literature. On the basis of karyotype, it has been proposed to exclude T. melanocephala, as well as of T. vitticeps and T. tibiamaculata, from the subcomplex, which shows fragmentation of the X sex chromosomes, thereby approaching the species of North America. Therefore, the present study aimed to determine the pattern of constitutive heterochromatin of $T$. melanocephala to provide new data on the cytotaxonomy of this vector of Chagas disease and especially to try to relate this species to some group, complex or subcomplex of triatomine species, aiding in their classification. This species showed no
\end{abstract}


constitutive heterochromatin in the autosomes or X sex chromosome, but only the Y sex chromosome. The number of chromosomes and heterochromatin pattern of $T$. melanocephala proved to be identical to that described for Panstrongylus lutzi. Thus, the present study demonstrated a tentative relationship between $T$. melanocephala and $P$. lutzi. However, we emphasize that other comparative studies should be conducted between these species, such as experimental crosses and molecular, enzymatic, morphological, and morphometric analyses to determine whether these species are actually evolutionarily related or if the number of chromosomes and the heterochromatin pattern emerged as homoplasies in T. melanocephala and P. lutzi.

Key words: Cytogenetics; Homoplasies; Taxonomy; Triatominae

\section{INTRODUCTION}

Triatomines are insects that are taxonomically included in the order Hemiptera and suborder Heteroptera within the family Reduviidae and subfamily Triatominae (Lent and Wygodzinsky, 1979). These organisms are of great medical importance, because all species that belong to the subfamily Triatominae are both bloodsucking and susceptible to infection by the protozoan Trypanosoma cruzi (Chagas, 1909) (Kinetoplastida, Trypanosomatidae) and are therefore potential vectors of Chagas disease (Noireau et al., 2009).

Specific identification and systematics of triatomines have been primarily based on morphological observations, mainly by light microscopy (Lent and Wygodzinsky, 1979). However, experimental crosses (Mendonça et al., 2014), molecular (Mendonça et al., 2009; Gardim et al., 2014), enzymatic (Costa et al., 1997), and cytogenetic (Panzera et al., 2010, 2012; Alevi et al., 2012a, 2013a; Succi et al., 2014) techniques have been used as important tools to aid in the classification of species.

Cytogenetic tools were used to differentiate Triatoma garciabesi from T. sordida, elevating it to the level of species (Panzera et al., 1997). Cytogenetic data, such as the number of chromosomes and the pattern of constitutive heterochromatin, were also used to group the species of the Brasiliensis subcomplex (Panzera et al., 2010; Alevi et al., 2012a,b, 2013a,b,c,d,e, 2014a,b). Thus, cytotaxonomy has turned out to be an important tool in the systematics of triatomines.

T. melanocephala is a species endemic to Brazil, specifically the States of Bahia, Paraíba, Pernambuco, Rio Grande do Norte, and Sergipe (Gurgel-Gonçalves et al., 2012). Recently, this organism was found infected with $T$. cruzi inside homes in the State of Pernambuco (Silva et al., 2012).

In principle, this species was included in the Brasiliensis subcomplex on the basis of morphological parameters and geographical layout (Schofield and Galvão, 2009), since there were no other relevant data available in the literature. Alevi et al. (2012a), according to karyotyping, proposed the exclusion of T. melanocephala, as well as T. vitticeps and T. tibiamaculata, from the subcomplex, which shows fragmentation of X sex chromosomes, thereby approaching the species of North America.

Therefore, the present study aimed to determine the pattern of constitutive heterochromatin of T. melanocephala to provide new data on the cytotaxonomy of this vector of Chagas 
disease and especially to try to relate this species with some group, complex or subcomplex of triatomine species, aiding in their classification.

\section{MATERIAL AND METHODS}

Seminiferous tubules of at least ten adult males of T. melanocephala, from the "Insectarium of Triatominae" established in Araraquara, São Paulo, were shredded, crushed and fixed in liquid nitrogen on a glass slide, and chromosomes were stained by C-banding (Sumner, 1972).

\section{RESULTS AND DISCUSSION}

The initial prophase showed a large chromocenter (Figure 1A, arrowhead) consisting of the sex chromosomes and some heterochromatic blocks dispersed in the nucleus (Figure $1 \mathrm{~A}$, arrows). According to metaphase I analysis (Figure 1B and C), we confirmed that males of T. melanocephala have the karyotype $2 \mathrm{n}=24\left(20 \mathrm{~A}+\mathrm{X}_{1} \mathrm{X}_{2} \mathrm{X}_{3} \mathrm{Y}\right)$. Moreover, by analyzing the metaphase I in polar view (Figure 1B and C) and side view (Figure 1D), we observed that this species shows no constitutive heterochromatin in autosomes and $\mathrm{X}$ sex chromosome (arrows), but only the Y sex chromosome (arrowheads).

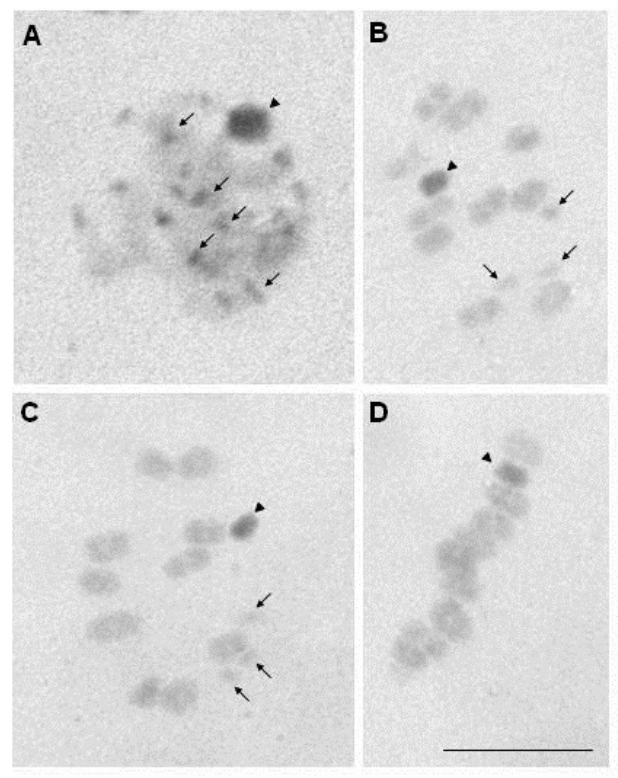

Figure 1. Seminiferous tubule of Triatoma melanocephala stained by C-banding. A. Initial prophase. Note a large chromocenter (arrowhead) and heterochromatic blocks (arrows) in the nucleus. B. C. D. Metaphase I. Note that the Y sex chromosomes (arrowheads) and that the X sex chromosomes (arrows) show no constitutive heterochromatin. Bar: $10 \mu \mathrm{m}$

The fragmentation of the sex chromosome $\mathrm{X}$ is a derived characteristic, since according to Ueshima (1966), the sex determination system in the ancestral subfamily Triatominae is XY. This peculiarity has been described in the literature in only four species, namely $T$. 
melanocephala (Alevi et al., 2012a), T. vitticeps (Schreiber and Pellegrino, 1950), T. eratyrusiformis (Panzera et al., 2010), and Panstrongylus lutzi (Santos, 2010). Of these species, only T. vitticeps and $P$. lutzi show the heterochromatin pattern described. Both, as observed in $T$. melanocephala, show no constitutive heterochromatin in autosomes. However, T. vitticeps shows constitutive heterochromatin in the X sex chromosome (Severi-Aguiar et al., 2006).

T. melanocephala and T. vitticeps species were considered synonymous by Lent and Wygodzinsky (1979). The only morphological characteristics that differentiate these species are the absence of testacea range in the head and the presence of two brown spots on the thorax (Sherlock and Guitton, 1980). Alevi et al. (2013b), by analyzing the heteropycnotic pattern, observed a direct correlation between the species, since $T$. melanocephala showed the same characteristics described by Severi-Aguiar et al. (2006) for T. vitticeps. Thus, although the number of chromosomes and the heteropycnotic pattern are identical, the presence of constitutive heterochromatin in the $\mathrm{X}$ sex chromosome can be considered a diagnostic characteristic of T. vitticeps, since T. melanocephala has no heterochromatic blocks in the $\mathrm{X}$ sex chromosome.

The heterochromatin banding pattern of T. melanocephala proved to be identical to that described for P. lutzi. Both showed heterochromatic blocks in prophase, the same number of chromosomes and the same arrangement of constitutive heterochromatin in the chromosomes, i.e., only the Y sex chromosome showed heterochromatin. Santos (2010) believe that possibly the heterochromatic bands observed in prophase are not seen during metaphase due to the high degree of condensation of chromosomes. However, we believe that the blocks do not really exist during metaphase, since the C-banding technique is specific for constitutive heterochromatin, and since it was totally clear that only chromosome heterochromatin was in the Y sex chromosome.

\section{CONCLUSION}

Thus, we demonstrated here a tentative relationship between T. melanocephala and P. lutzi. However, we emphasize that other comparative studies should be conducted between these species, such as experimental crosses and molecular, enzymatic, morphological, and morphometric analyses to determine whether these species are actually evolutionarily related or if the number of chromosomes and the heterochromatin pattern emerged as homoplasies in T. melanocephala and P. lutzi.

\section{ACKNOWLEDGMENTS}

Research supported by Fundação de Amparo à Pesquisa do Estado de São Paulo (FAPESP; Process \#2012/22361-2) and Conselho Nacional de Desenvolvimento Científico e Tecnológico (CNPq).

\section{REFERENCES}

Alevi KCC, Mendonça PP, Pereira NP, Rosa JA, et al. (2012a). Karyotype of Triatoma lenti (Hemiptera: Triatominae), a potential Chagas vector. Genet. Mol. Res. 11: 4278-4284.

Alevi KCC, Mendonça PP, Pereira NP, Rosa JA, et al. (2012b). Karyotype of Triatoma melanocephala Neiva and Pinto (1923). Does this species fit in the Brasiliensis subcomplex? Infect. Genet. Evol. 12: 1652-1653.

Alevi KCC, Mendonça PP, Pereira NP, Guerra AL, et al. (2013a). Distribution of constitutive heterochromatin in two species of triatomines: Triatoma lenti Sherlock and Serafim (1967) and Triatoma sherlocki Papa, Jurberg, Carcavallo, 
Cerqueira \& Barata (2002). Infect. Gen. Evol. 13: 301-303.

Alevi KC, Mendonça PP, Pereira NP, Rosa JA, et al. (2013b). Spermatogenesis in Triatoma melanocephala (Hemiptera: Triatominae). Genet. Mol. Res. 12: 4944-4947.

Alevi KCC, Mendonça PP, Pereira NP, Rosa JA, et al. (2013c). Análise das possíveis Regiões Organizadoras Nucleolares e da atividade nucleolar em Triatoma melanocephala e T. lenti, importantes vetores da doença de Chagas. Rev. Cienc. Farm. Básica Apl. 34: 417-421.

Alevi KCC, Mendonça PP, Pereira NP, Rosa JA, et al. (2013d). Heteropyknotic filament in spermatids of Triatoma melanocephala and T. vitticeps (Hemiptera, Triatominae). Inv. Rep. Dev. 58: 9-12.

Alevi KCC, Mendonça PP, Pereira NP, Fernandes AL, et al. (2013e). Analysis of spermiogenesis like a tool in the study of the triatomines of the Brasiliensis subcomplex. C R Biol. 336: 46-50.

Alevi KCC, da Rosa JA and de Azeredo-Oliveira MT (2014a). Spermatogenesis in Triatoma melanica Neiva and Lent, 1941 (Hemiptera, Triatominae). J. Vector Ecol. 39: 231-233.

Alevi KCC, Rosa JA and Azeredo-Oliveira MT (2014b). Cytotaxonomy of the Brasiliensis subcomplex and the Triatoma brasiliensis complex (Hemiptera: Reduviidae: Triatominae). Zootaxa 3838: 583-589.

Costa J, Freitas-Sibajev MG, Marchon-Silva V, Pires MQ, et al. (1997). Isoenzymes detect variation in populations of Triatoma brasiliensis (Hemiptera: Reduviidae: Triatominae). Mem. Inst. Oswaldo Cruz 92: 459-464.

Gardim S, Almeida CE, Takiya DM, Oliveira J, et al. (2014). Multiple mitochondrial genes of some sylvatic Brazilian Triatoma: non-monophyly of the T. brasiliensis subcomplex and the need for a generic revision in the Triatomini. Infect. Genet. Evol. 23: 74-79.

Gurgel-Gonçalves R, Galvão C, Costa J and Peterson AT (2012). Geographic distribution of Chagas disease vectors in Brazil based on ecological niche modeling. J. Trop. Med. 2012: 705326.

Lent H and Wygodzinsky P (1979). Revision of the Triatominae (Hemiptera: Reduviidae) and their significance as vector of Chagas's disease. Bull. Am. Mus. Nat. Hist. 163: 123-520.

Mendonça VJ, da Silva MT, de Araujo RF, Junior JM, et al. (2009). Phylogeny of Triatoma sherlocki (Hemiptera: Reduviidae: Triatominae) inferred from two mitochondrial genes suggests its location within the Triatoma brasiliensis complex. Am. J. Trop. Med. Hyg. 81: 858-864.

Mendonça VJ, Alevi KC, Medeiros LM, Nascimento JD, et al. (2014). Cytogenetic and morphologic approaches of hybrids from experimental crosses between Triatoma lenti Sherlock \& Serafim, 1967 and T. sherlocki Papa et al., 2002 (Hemiptera: Reduviidae). Infect. Genet. Evol. 26: 123-131.

Noireau F, Diosque P and Jansen AM (2009). Trypanosoma cruzi: adaptation to its vectors and its hosts. Vet. Res. 40: 26.

Panzera F, Hornos S, Pereira J, Cestau R, et al. (1997). Genetic variability and geographic differentiation among three species of Triatomine bugs (Hemiptera-Reduviidae). Am. J. Trop. Med. Hyg. 57: 732-739.

Panzera F, Perez R, Panzera Y, Ferrandis I, et al. (2010). Cytogenetics and genome evolution in the subfamily Triatominae (Hemiptera, Reduviidae). Cytogenet. Genome Res. 128: 77-87.

Panzera Y, Pita S, Ferreiro MJ, Ferrandis I, et al. (2012). High dynamics of rDNA cluster location in kissing bug holocentric chromosomes (Triatominae, Heteroptera). Cytogenet. Genome Res. 138: 56-67.

Santos SM (2010). Estudo Citogenético de Quatro Espécies de Triatomíneos (Hemiptera:Reduviidae). DSc thesis, Universidade Federal de Viçosa, Viçosa.

Schofield CJ and Galvão C (2009). Classification, evolution, and species groups within the Triatominae. Acta Trop. 110: 88-100.

Schreiber G and Pellegrino J (1950). Eteropicnosi di autosomi come possibile meccanismo di speciazione. Sci. Genet. 3: 215-226.

Severi-Aguiar GD, Lourenço LB, Bicudo HE and Azeredo-Oliveira MT (2006). Meiosis aspects and nucleolar activity in Triatoma vitticeps (Triatominae, Heteroptera). Genetica 126: 141-151.

Sherlock ÍA and Guitton N (1980). Fauna Triatominae do estado da Bahia, Brasil: IV - Triatoma melanocephala Neiva \& Pinto, 1923. Mem. Inst. Oswaldo Cruz 75: 23-31.

Silva MB, Barreto AV, Silva HA, Galvão C, et al. (2012). Synanthropic triatomines (Hemiptera, Reduviidae) in the state of Pernambuco, Brazil: geographical distribution and natural Trypanosoma infection rates between 2006 and 2007. Rev. Soc. Bras. Med. Trop. 45: 60-65.

Succi M, Alevi KCC, Mendonça PP, Bardella VB, et al. (2014). Spermatogenesis in Triatoma williami Galvão, Souza and Lima (1956) (Hemiptera, Triatominae). Inv. Rep. Dev. 58: 124-127.

Sumner AT (1972). A simple technique for demonstrating centromeric heterochromatin. Exp. Cell Res. 75: 304-306.

Ueshima N (1966). Cytotaxonomy of the Triatominae (Reduviidae: Hemiptera). Chromosoma 18: 97-122. 